\title{
CAIO FERNANDO ABREU E AS HISTÓRIAS DE UM NOVO TEMPO: EPISTOLOGRAFIA E LITERATURA BRASILEIRA
}

\begin{abstract}
Mara Lúcia Barbosa da Silva ${ }^{1}$
Resumo: Para Walnice Nogueira Galvão (2008), a disseminação do computador matou a carta e como consequência transformou-a em um precioso objeto de estudo. O vasto conjunto de cartas de Caio Fernando Abreu tem sido corpus de diversas pesquisas. $\mathrm{Na}$ epistolografia do autor, podemos observar as três vertentes de estudos propostas por Moraes (2006) e em nosso recorte neste trabalho focaremos uma delas, os bastidores do lançamento da antologia Histórias de um novo tempo através da correspondência entre três dos autores da obra. Essa antologia tinha a intenção de reunir uma nova e promissora geração de escritores brasileiros na década de 1970: Luiz Fernando Emediato, Jeferson Ribeiro de Andrade, Antonio Barreto, Domingos Pellegrini, Julio César Monteiro Martins e Caio Fernando Abreu. Utilizaremos como corpus de pesquisa o livro de cartas de Caio F., organizado por Moriconi (2002), correspondência do acervo do autor no Delfos/PUCRS e edições de O pasquim, entre outros materiais.

Palavras-chave: Correspondência; Caio Fernando Abreu; Histórias de um novo tempo; Memória; Literatura Brasileira.
\end{abstract}

Abstract: As Walnice Nogueira Galvão (2008) compellingly argues, computer dissemination murdered letter and, consequently, turns it into a wealthy subject matter of research. In this sense, the wide set of Caio Fernando Abreu's letters have been the corpus of a growing output of publications. Within the author's epistography, one may notice three varieties of studies proposed by Moraes (2006) and, in this paper, attention is given to one of them, the backstage at the launch of the anthology Histórias de um novo tempo, taking into account the correspondence among three authors responsible for the publication. The anthology attempted to gather a new and promising generation of Brazilian writers in the 1970's: Luiz Fernando Emediato, Jeferson Ribeiro de Andrade, Antonio Barreto, Domingos Pellegrini, Julio César Monteiro Martins, and Caio Fernando Abreu. The corpus consists of Caio F.'s book of letters, organized by Moriconi (2002), in addition to the author's correspondence available in Delfos/PUCRS and editions of $O$ pasquim, among other materials.

Keywords: Correspondence; Caio Fernando Abreu; Histórias de um novo tempo; Memory; Brazilian Literature.

1 Bolsista PNPD/Capes do Programa de Pós-Graduação em Letras da Universidade Federal de Santa Maria (2011-2016). E-mail: mlubs.br@gmail.com. 
Caio Fernando Abreu era um "escrevinhador" de cartas e essas, que são nosso objeto de estudo, já receberam algumas organizações, como a seleção realizada por Italo Moriconi, Caio Fernando Abreu: cartas, de 2002; os três volumes Caio 3D: o essencial da década, cada um correspondendo a uma (anos 1970, 1980 e 1990), de 2006; os livros de Paula Dip, Para sempre teu, Caio F: cartas, conversas, memórias de Caio Fernando Abreu, de 2011; e Numa hora assim escura, que reúne cartas de Caio F. para Hilda Hilst, de 2016.

As correspondências, ativa e passiva, de Caio Fernando Abreu estão distribuídas por, pelo menos, três centros de pesquisa no Brasil: na Fundação Casa de Rui Barbosa, no Rio de Janeiro/RJ, cujo material está apenas arquivado; no Centro de Documentação Alexandre Eulálio (CEDAE)/Unicamp, em Campinas/SP, onde há disponíveis para consulta cartas do autor para a escritora Hilda Hilst, entre 1969 e 1995, sendo a maioria da década de 1970; e no Delfos - Espaço de documentação e memória cultural da PUCRS, Porto Alegre/RS, onde dos 2.780 itens existentes, 1.542 referem-se à categoria correspondência.

Corroborando a relevância da conservação de arquivos e das seleções epistolográficas realizadas, Walnice Nogueira Galvão, em entrevista à revista Teresa, chama a atenção para o desaparecimento da carta como uma forma de comunicação e da sua transformação em um precioso objeto de estudo: "A disseminação do computador acabou com a carta e, na hora em que a matou, descobriram que era um objeto preciso". (GALVÃO, 2008, p. 15).

Segundo Marcos Moraes (2006), a correspondência de escritores pode abrir-se para uma tríade exploratória que tanto pode considerar essa como uma forma de expressão testemunhal - que pode definir um perfil biográfico do autor ou uma maneira de acompanhar a movimentação dos bastidores da vida literária - quanto se apresentar como um laboratório de criação ao documentar a (re)elaboração de uma obra. Na correspondência de Caio Fernando Abreu, além dessa divisão, é possível identificar outras perspectivas de estudo, como, por exemplo, a da correspondência como espaço de ficcionalização e lugar de testemunho de questões sociais, políticas e econômicas.

Nosso recorte neste artigo vai incursionar pela segunda possibilidade de estudo do gênero epistolar elencada por Moraes, ao investigar as circunstâncias que envolveram a edição, o lançamento e a divulgação da antologia Histórias de um novo tempo, que reuniu uma nova e promissora geração de escritores brasileiros na década de 1970: os mineiros Luiz Fernando Emediato, Jeferson Ribeiro de Andrade e Antonio Barreto; o paranaense Domingos Pellegrini; o niteroiense Julio César Monteiro Martins; e o gaúcho Caio Fernando Abreu. O livro foi ilustrado pelo artista plástico Marcos Coelho Benjamin.

Histórias de um novo tempo apresenta dois contos de cada um dos escritores, parte das histórias, através de personagens, espaços, enredos e intrigas diferentes, gira em torno da situação política do Brasil pós-64, alguns de maneira mais explícita, como em Radinho de pilha, de Barreto, A mãe, de Pellegrini, Morte e angústia para quem tem fome, de Jeferson de Andrade, Método, de Julio Martins e Longe da terra, de Emediato, nos quais são representados o exílio, a resistência, a perseguição, a repressão e a violência por meio situações vividas por personagens apartadas de sua pátria, sofrendo tortura, sendo compulsivamente perseguidas, tendo reprimidas às suas reivindicações.

Outras das histórias entrelaçam-se, de alguma forma, com o tema da repressão e do estado de coisas daquele momento no Brasil, na medida em que trazem à baila assuntos que 
são circundantes, como a violência urbana, em Sujo de bosta, de Barreto; a opressão que se estendia para outras áreas além daquelas que estavam diretamente envolvidas na resistência, como em A maior ponte do mundo, de Pellegrini, que narra a saga de trabalhadores obrigados a trabalhar em jornadas desumanas na construção da Ponte Rio-Niterói, entre 1969 e 1974. Essa temática também foi abordada em A perna, de Emediato, que apresenta a vida ordinária de um homem que por ter participado de uma greve foi torturado e perdeu, acidentalmente, a perna direita enquanto trabalhava; assim, ele vive de uma pensão e dedica-se a assediar estudantes em coletivos. Os contos de Caio Fernando Abreu narram, de forma subjetiva, as consequências que um sistema opressor impõe sobre a vida dos sujeitos em uma sociedade econômica e emocionalmente sucateada.

O prefácio da obra enaltece a sua originalidade e apresenta os seus jovens autores:

Histórias de um novo tempo surge como um livro histórico na literatura brasileira. Não apenas porque enfoca a realidade de um modo abrangente e inusitado, mas principalmente porque é o primeiro grande livro de uma geração que se formou nesta ultima década da história do País.

\section{$[\ldots]$}

Histórias de um novo tempo, que o PASQUIM apresenta agora ao leitor brasileiro, é um livro de autores que tiveram a capacidade de resistir e de construir uma obra cujo compromisso maior não é com a passividade e a tolerância anêmica, mas sim com a reconstrução do homem através da retratação artística da infelizmente trágica comédia brasileira. (MARTINS ET AL. 1977, p. 6-7)

Esse pouco conhecido episódio da história da literatura brasileira terá como fontes de investigação documentos, como uma carta de Domingos Pellegrini para todos os outros cinco escritores, depositada no Delfos; três cartas de Caio Fernando Abreu para Luiz Fernando Emediato, publicadas em Caio Fernando Abreu: cartas; duas cartas publicadas na sessão dedicada aos leitores no jornal O Pasquim, uma do leitor Rogério Monteiro e outra de Caio F. Além dessas correspondências, utilizaremos ainda uma entrevista concedida pelos autores também ao jornal O Pasquim, fato gerador das cartas de Monteiro e de Caio; e duas reportagens disponíveis apenas na internet, uma sobre Jeferson Ribeiro de Andrade, no sítio Escritório de histórias, e outra com o relato de Luiz Fernando Emediato no sítio da sua editora Geração Books (Geração Editorial), no qual o editor narra como conheceu Caio F., a formação do grupo, a sua dissolução e o que aconteceu com cada um dos seus integrantes.

No Delfos, não há cartas de ou para Emediato, mas existem duas correspondências de Domingos Pellegrini, uma delas, já citada, apresenta reflexões sobre um possível projeto literário desse grupo de escritores. Há também duas cartas de Jeferson de Andrade, da década de 1980, posteriores, portanto, ao momento do lançamento de Histórias de um novo tempo. E constam ainda 10 itens relacionados a Julio César Monteiro, dos quais seis são cartas. Em uma delas, Martins comunica que o livro Histórias de um novo tempo deve sair 
até o fim de 1976 e, em outra, de 5 de julho de 1976, além de questões acerca da antologia, ele elabora algumas reflexões sobre como deveria ser a literatura.

Um olhar sobre Jeferson de Andrade é o título da matéria que, além de contar a trajetória do jornalista, editor e escritor, relata também a reunião de um grupo de jovens escritores "marginais", de vários estados do país, em torno da edição de um livro, Histórias de um novo tempo. Na reportagem de Emediato, além do relato pessoal, o autor publica, em anexo, nove cartas que Caio lhe enviara, cinco delas já presentes no livro organizado por Moriconi; as outras quatro, inéditas. Não há, no sítio, a data de redação ou de publicação do relato, mas, pelas informações constantes nos textos - como: "Minha memória não consegue recuperar os termos de minha primeira carta para Caio Fernando Abreu, no início de 1976" [EMEDIATO, 2001?, on-line], no parágrafo final da primeira parte da reportagem podemos inferir que esse foi escrito e/ou, pelo menos, publicado em 2001.

As reportagens e as cartas proporcionam acesso a informações e fatos que nos permitem organizar uma história do lançamento dessa antologia, como a percepção de Caio sobre uma possível publicação, em carta para Emediato, em 6 de outubro de 1976, em um período que antecede o contrato com a Codecri:

Cheguei em casa do jornal e tinha uma coincidência curiosa e agradável - uma carta do Julio Cesar, outra do Pellegrini, outra sua. Julio Cesar tinha mandado um telegrama sobre a transação com o Pasquim: eu não acreditei e continuo não acreditando muito. Sou meio cético com essas coisas, talvez os deuses pasquinianos tenham dito que sim, com a intenção de enrolar-enrolar ad infinitum, como de costume. Mas como sou também paranóico e inseguro até as raias da demência (gosto muito desta palavra), espero que seja verdade. Principalmente porque merecemos, não é mesmo? Falando sério: seria muito bom (eu acho é que não estou querendo me entusiasmar muito, como tenho vontade, com medo de um desmentido). Deixa andar. Forças! (ABREU, 2002, p. 479)

E a de Emediato, em seu relato, quando apresenta os seus parceiros de publicação:

Os escolhidos foram seis jovens contistas que estavam então se notabilizando por seu talento precoce: o próprio Jéferson, um jornalista combativo e escritor sem grande brilho; o poeta mineiro Antonio Barreto, 22 anos, que começava a escrever ficção; o paranaense Domingos Pellegrini, 28 anos; o carioca Julio César Monteiro Martins, de apenas 21 anos; o gaúcho Caio Fernando Abreu, 27 anos, e eu, 25 anos. Quando publiquei meu segundo livro de contos, Os lábios úmidos de Marilyn Monroe, pela Ática, dediquei-o aos seis, a quem chamava de "os paladinos do Oeste". [2001?, on-line].

O livro com os novos contistas foi a segunda publicação da editora Codecri, ligada ao jornal O Pasquim, e ocorreu com o aval de Ziraldo, sob a supervisão de Jeferson Ribeiro de Andrade, então, seu editor. O jornal, que se opunha ao regime militar, fora criado, em 1969, por um grupo constituído por jornalistas, cartunistas e chargistas do "naipe" de Ziraldo, 
Jaguar, Fortuna, Millôr Fernandes, Sérgio Cabral, Luís Carlos Maciel e Tarso de Castro, entre outros.

A entrevista com os jovens autores para O pasquim, intitulada Quatro histórias de um novo tempo, cuja chamada de capa era Entrevistão: ala jovem da literatura dá seu recado, fez parte da edição 422, de 29 de julho a 4 de agosto de 1977, quando a segunda tiragem da obra já havia sido publicada. Logo no começo da conversa, Félix de Athayde, um dos entrevistadores, junto com Cícero Sandroni (jornalista, escritor e membro da Academia Brasileira de Letras) e Eglê Malheiros (escritora, tradutora), chama a atenção para o fato de todos os autores serem da província, exceto Julio Martins, de Niterói, no Rio de Janeiro. Athayde pergunta como se conheceram, ao que Antonio Barreto responde que se reuniram "porque havia uma afinidade ideológica de pensamento e através de correspondências, cartas e tal" (PASQUIM, 1977, p. 6). O mesmo declara Emediato em seu relato: “Trocávamos cartas febrilmente. Ansiávamos por nos conhecer pessoalmente, o que se deu com o lançamento da antologia" [2001?]. Fato confirmado por Caio em carta, de 8 de março de 1977, para Emediato: "[...] Pintaram mil caronas para o Rio e eu segurei, pensando justamente no lançamento, 'economizando' as feriazinhas. Julio César já falou que posso ficar lá. Uma vontade INCRÍVEL de conhecer vocês. [...]”. (ABREU, 2002, p. 485).

Na segunda página da entrevista há um box, redigido por Jaguar, no qual ele faz uma pequena apresentação dos autores, que é ilustrada por uma foto de Jefferson, Julio Cesar, Emediato e Caio:

São quatro dos seis autores de Histórias de um novo tempo (Antonio Barreto teve que sair no meio da entrevista), o livro de contos que a Codecri lançou e que teve um surpreendente sucesso de público - já vendeu dez mil exemplares - e um grande sucesso de crítica. Idade média: 24 anos. Caio Fernando Abreu, gaúcho, Luiz Fernando Emediato, mineiro, Júlio Cesar Monteiro Martins, carioca, e Jeferson Ribeiro de Andrade, mineiro, demonstram uma verdade que a gente já sabe, mas é sempre animador constatar: que nada - nem a repressão oficial, nem as dificuldades materiais - pode impedir o aparecimento e a afirmação de novos talentos criativos pelaí. Domingos Pellegrini Jr., um dos seis autores, não pôde viajar para o Rio. Os entrevistadores foram Félix de Athayde, da patota, Cícero Sandroni e Eglê Malheiros, diretores da revista "Ficção" - (Jaguar). (PASQUIM, 1977, p. 7).

$\mathrm{Na}$ ocasião da entrevista, a obra já vendera 10 mil exemplares, mas houve a expectativa de que a antologia fosse ser lançada com 60 mil, como comenta Domingos Pellegrini, em carta de $1^{\circ}$ de outubro de 1976, de Londrina, com cópias para todo o grupo: "Acabo de receber telefonema de Julio comunicando que a Editora Codecri, do Pasquim, lançará História de Um Novo Tempo com 60.000 exemplares. Ainda estou pasmo e não posso acreditar numa tiragem de tal proporção; se fossem 20.000, eu já acharia ótimo." (PUCRS/DELFOS, 1976). E, de fato, o que já seria ótimo aconteceu, Histórias de um novo tempo foi um sucesso de lançamento; segundo Luiz Fernando Emediato, "saiu com 20.000 exemplares e vendeu tudo em 15 dias. A segunda edição, mais 10.000, também acabou logo. Antes de sair a ter- 
ceira edição quase todo mundo já tinha brigado por algum motivo" [2001?, on-line].

Uma das "querelas" entre o grupo ocorreu justamente por conta da entrevista publicada pouco tempo depois do lançamento; sobre isso, diz Emediato: "A entrevista saiu com trechos naturalmente cortados (para caber nas duas páginas do jornal) e Caio odiou. Escreveu uma carta ao Pasquim, que respondeu, como de hábito, mandando-o lamber sabão ou algo parecido. A partir daí ninguém se entendeu mais" [2001?]. A reação de Caio quanto à edição da entrevista é mencionada em carta para Emediato, de 22 de agosto de 1977:

Escrevi duas cartas: uma à seção de cartas daquele jornaleco careta e reacionário, de três páginas, muito agressiva, dizendo absolutamente tudo que penso sobre eles e sobre os cortes feitos na entrevista, (estranho que praticamente não cortaram nada das palavras de vocês, só das minhas)". Outra ao Jeferson, dizendo que absolutamente não permito que a Codecri ou seja quem for se dê tais direitos sobre um texto meu. Que não assino nem devolvo aquele papel (eu sou tão desligado que ainda não tinha lido). E também quero saber da possibilidade de retirar meus contos de uma possível terceira edição. (ABREU, 2002, p. 493).

A carta de Caio para o jornal foi motivada pelos cortes de suas falas na entrevista e por ter tomado conhecimento, através de um amigo, de uma carta enviada pelo leitor Rogério Monteiro para a seção de cartas do jornal, número 424, de 12 a 18 de agosto de 1977, reclamando da forma como a entrevista havia sido conduzida, e da resposta irônica e agressiva que recebeu do responsável pela seção, Edélsio Tavares, pseudônimo do escritor e jornalista Ivan Lessa. Dizia a carta de Monteiro:

BAIANO DE FIBRA, BOM DE CUCA E CORAÇÃO - Carta do leitor Rogério Monteiro:

Escuta Edélsio, eu não me ligo nesse negócio de ficar escrevendo cartinhas, mas resolvi abrir uma exceção para levar até vocês - editores de uma das poucas fontes de informação "legíveis" do país - meu protesto pela bundamolice que foi a entrevista "Quatro Histórias do Nosso Tempo" (PASQUIM 422). Digo isso porque conheço bem a obra de Caio Fernando Abreu e garanto que ele sozinho teria condições de dar um recado melhor nas quatro páginas gastas com a matéria. Dos demais participantes conheço apenas os trabalhos apresentados no livro editado pela Codecri. Mas acredito que também teriam muito mais a dizer e só não o fizeram por serem cortados, agredidos e principalmente condicionados pelos entrevistadores (destaque para aquela besta do Cícero Sandroni) a colocar todo o papo no plano político direto. Acho que vocês estão velhos e..." "ROGÉRIO MONTEIRO” (Salvador (?), BA (?)). (PASQUIM, 1977, p. 2). 
A que se segue, no periódico, a irônica resposta do Pasquim:

Resposta:

Concurso de contos, "Rogério Monteiro", não é aqui, não. E qualquer tentativa de colocar qualquer papo em qualquer tipo de plano político direto é sempre saudável, "Rogério Monteiro". "Você" acha que eles foram agredidos, é? Antes sesse. Ao menos assim poderiam, na base do pau, aprender alguma coisa que não fosse ler livrinho ou revistinha estrangeira. Vá emborgezar um Cortázar, "Rogério Monteiro". E teu sotaque, além do mais, é de Minas, nunca da Bahia. Te flagrei boneco!!! (?)). (PASQUIM, 1977, p. 2).

A longa carta enviada por Caio Fernando Abreu ao Pasquim, dirigida à Edélsio Tavares/Ivan Lessa, que saiu no número 428, de 09 a 15 de setembro de 1977, começa da seguinte maneira:

Porto Alegre, 18 de agosto de 1977

Seu Edélsio (?):

Como não costumo ler $\mathrm{O}$ Pasquim, somente hoje, através de outra pessoa, tomei conhecimento da carta enviada a vocês por Rogério Monteiro, a respeito da entrevista sobre Histórias de Um Novo Tempo. E também da resposta Grossa e imbecil como, suponho - já que não perco tempo com imprensa pseudoliberal, chauvinista e reacionária -, costumam ser as respostas de vocês. [...]. (PASQUIM, 1977, p. 12).

Nessa correspondência, o autor aborda, além da questão surgida por conta da carta do leitor, diversos outros assuntos que o incomodavam em relação à publicação e, mais especificamente, aos seus articulistas e colunistas. Caio F. reclama de aspectos que dizem respeito especificamente à sua pessoa, como os cortes na sua entrevista e os comentários que considerou de caráter censório quanto às suas leituras e formação, à sua sexualidade e ao seu trabalho de criação literária; além disso, expõe outros tópicos, como a falta de apoio efetivo Codecri no que se referiu ao lançamento e à divulgação da obra, deixando os “"pobres jovens a quem estamos dando uma chance"' em segundo plano. O autor afirma também que os conceitos políticos deles estavam ultrapassados, que havia um abismo entre suas gerações e que o diálogo era impossível; chama O Pasquim de careta e o compara à revista Manchete, semanário surgido no Brasil, em 1952, focado no fotojornalismo.

O anúncio do livro de Octávio Ribeiro, Barra pesada, na parte inferior da página na qual foi publicada a carta de Caio - ele reclama, na sua carta, que seus nomes não haviam sido divulgados no lançamento e que restaram à sombra de Ribeiro e sua obra - e a resposta lacônica de Lessa - expressa na frase: "British é com um t só" - que tem a clara intenção de ironizar a declaração de Caio na carta quando esse diz: “[...] leio em inglês, espanhol, italiano, francês, entendo alguma coisa de sueco e estou estudando alemão. [...]" (PASQUIM, 1977, p. 12), demonstram "o modo pasquim de ser".

Não podemos desconsiderar que a publicação da carta de Caio, com seu texto integral, 
sozinha, como um elemento extra no jornal, em outro espaço que não aquele dedicado à seção de cartas, com o título História de um novo tempo: um novíssimo contista brasileiro, denota que alguma importância foi atribuída à opinião do autor.

As relações entre o grupo, portanto, dissolveram-se logo após a publicação do livro, da entrevista e de algumas indisposições pessoais; assim ruiu também o ambicioso projeto de constituição de uma nova vanguarda na literatura brasileira, conforme narra Emediato:

Tinha sido bom até ali. Nós, os seis “paladinos", às vésperas da glória - sair numa antologia com as bênçãos do Pasquim - imaginávamos lançar um manifesto literário e até tentar repetir, em algum lugar (Rio, Belo Horizonte, São Paulo), a Semana da Arte Moderna de 1922! Acho que a idéia foi de Julio César Monteiro Martins, nosso maior megalômano. [2001?, on-line].

Independentemente de quem teve a ideia do Manifesto Neo-realista ou de uma possível Semana, é certo que ela agradava a outros dos membros do grupo. Na já referida carta de Domingos Pellegrini enviada aos outros cinco "paladinos do Oeste", o autor discorre sobre dois aspectos do manifesto, através do qual pretenderiam dar visibilidade ao que seriam as suas propostas estéticas e políticas para a literatura.

A posição de Caio Fernando Abreu difere-se da dos demais por conta de certas orientações do "manifesto". Acreditamos que Caio opôs-se a esse, especialmente, no que se constitui como um possível "patrulhamento" do seu ato criativo, o que pode ser inferido pela palavra "mesmo" escrita em caixa alta em "Eu não sei MESMO se sou contra o individualismo" e ao elencar as influências literárias que recebeu, ao longo de sua formação, de cunho marcadamente intimistas.

Olhe, na cópia que você enviou do Manifesto Neo-Realista aconteceu um engano: as duas folhas enviadas são cópias da mesma folha, entende? Isto é: as duas são a segunda página do manifesto, pegando creio que o final do item cinco até o oito. Portanto, não deu pra fazer uma idéia. Mas vou ser bem franco: eu realmente não sei. Sou cético, pessimista - acho que somos todos bons escritores, mas acho também meio megalômano nos supormos a nata das natas, saca? Acho inclusive uma atitude elitista. Somos bons, mas somos jovens e só o tempo é que pode dizer se a gente vai conseguir, pelo menos, continuar escrevendo. E às vezes, confesso, até mesmo isso me parece muito difícil. Então não sei, companheiro. Também tenho uma dificuldade incrível pra me definir. A primeira frase, "contra o individualismo", de cara já me grila. Eu não sei MESMO se sou contra o individualismo. Em processo terapêutico, e com uma formação literária onde as influências maiores creio que foram Lispector, Virginia Woolf, Proust, Drummond, Pessoa, por aí - não sei se posso afirmar isso, me entende? Pelo menos agora, eu não me sinto seguro. Por outro lado, há itens inteligentíssimos: “... literatura nacional, mas não xenófoba, populista ou demagógica. Assimilar e deglutir de forma crítica o que, não sendo nacional, for universalmente necessário" - por exemplo, acho perfeito. Quem sabe uma reformulação, não sei. Se vocês acharem que não é possível 
reformular, vamos supor, e que discorde de muitas outras coisas, vai sem o meu nome, por mim tudo bem. (ABREU, 2002, p. 484-485).

Pela postura de Caio quanto ao manifesto, tornam-se perceptíveis as suas diferenças em relação ao restante do grupo. Diferenças que já ficaram aparentes na entrevista quando foram mencionadas questões sofre os enfoques sociais de alguns dos textos e os aspectos psicológicos dos textos de Caio, que diz não estar "preocupado com uma literatura engajada" (PASQUIM, 1977, p. 8) e que a sua "forma de resistir é denunciar as formas de opressão" (PASQUIM, 1977, p. 8). Além das divergências que começaram a aparecer de maneira mais acentuada entre os "paladinos do oeste", eles também eram afetados por pressões externas, como conta Emediato:

A coisa degringolou quando, diante do inusitado sucesso de Histórias de um Novo Tempo, os velhos senhores e senhoras do arraial literário começaram a caluniar os jovens contistas. Por que aqueles seis, e não outros? Por que não tinham sido 10, ou 20, os escolhidos? E por aí vai. Disgusting, diria Caio. Cada um, então, seguiu o seu caminho. A editora Codecri cresceu rapidamente e desinteressouse do best seller de autores tão complicados. O livro parou na terceira edição. [2001?, on-line]

Independentemente dos resultados e da continuidade da publicação da antologia, todos os seis autores empreenderam carreiras literárias, alguns com mais, outros menos, notoriedade. Antônio Barreto (1954), ao longo de sua carreira, colaborou em várias publicações nacionais e internacionais, como O Pasquim, Jornal do Brasil, O Estado de S. Paulo, El Clarín, Zidcht, entre outros. A sua produção literária é bastante diversificada, ele transita entre poesia, conto, romance e literatura infantojuvenil e já recebeu diversas premiações nacionais, como o Prêmio Jabuti, e internacionais, como o Ezra Jack Keats, nos EUA.

Domingos Pellegrini Jr. (1949), que é romancista, contista, cronista, poeta, jornalista e publicitário, passou a maior parte de sua vida em Londrina, onde mora atualmente. Além das atividades literárias, ele desenvolveu também atividades políticas, entre 1989 e 1992, atuou como Secretário de Cultura do município de Londrina. Do mesmo modo que Antonio Barreto, Pellegrini também tem uma vasta e diversificada produção literária, escreve: contos, novelas, romances, poesia e livros infantojuvenis. Pellegrini ganhou dois Prêmios Jabutis, em 1977, na categoria conto com O Homem vermelho (seu primeiro livro) e, em 2001, com O caso da chácara chão, na categoria romance.

Jeferson Ribeiro de Andrade (1947-2013) aliava a sua atividade literária com a editorial. Ele foi o responsável pela transferência de Carlos Drummond de Andrade da editora José Olympio para a Record, foi também editor da Codecri e auxiliou Luiz Fernando Emediato na estruturação da editora "Geração", posteriormente Geração Editorial. Sua obra Anna de Assis: história de um trágico amor, que conta a história de traição e morte envolvendo Euclides da Cunha e sua mulher Anna de Assis, tornou-se um best-seller. Jeferson criou a obra com base em cartas e documentos cedidos por Judith Ribeiro de Assis, filha de Anna.

Julio Cesar Monteiro Martins (1955-2014) foi engajado nas questões de direitos hu- 
manos, atuou no massacre da Candelária no Rio de Janeiro; além disso, foi um dos fundadores do Partido Verde brasileiro e do movimento ambientalista Os Verdes. Atuou como professor universitário no Brasil e na Europa (Portugal e Itália), locais onde ensinou língua portuguesa e tradução literária. Escreveu sua obra em língua portuguesa entre 1975 e 1994, e de 1998 em diante escreveu e publicou em italiano, pois se transferiu para a Itália, país no qual faleceu.

Luiz Fernando Emediato (1951) trabalhou na sucursal mineira do Jornal do Brasil, no Estado de S. Paulo, onde permaneceu por 10 anos. Dirigiu o jornalismo do SBT, no qual "criou" o âncora Boris Casoy. Em 1991, deixou as redações para montar sua empresa a Geração Editorial, na qual ainda atua. Durante sua carreira jornalística, recebeu premiações importantes, como, em 1982, o Prêmio Esso, e o Prêmio Internacional de Jornalismo Rei de Espanha. Além da atividade editorial, Emediato dedicou-se também à consultoria política e à participação, como voluntário, em conselhos governamentais, privados e paraestatais.

Caio Fernando Abreu (1948-1996) iniciou os cursos de Letras e Artes Dramáticas, mas os abandonou ambos para se dedicar ao trabalho jornalístico no Centro do país em revistas, como Pop, Nova, Veja e Manchete. Ele foi editor da revista Leia Livros e colaborou nos jornais Correio do Povo, Zero Hora e Folha de São Paulo, entre Os "rastros" (GINZBURG, 2012) buscados nas correspondências ativas e passivas de Caio Fernando Abreu e nos demais materiais nos permitiram conhecer um pouco e uma parte da história dessa antologia e de seus autores. A organização desses "rastros" ratifica também a impressão de que a escrita e o escrever eram vitais para Caio, o que se comprova pelo fato de que ele nunca parou de escrever, fosse a sua literatura, que se pode constatar pela extensão de sua obra, pelas suas cartas e outros tantos escritos como também pelos seus "biscates culturais", que lhe permitiram sobreviver ao longo do tempo.

Torna-se patente também a posição do autor diante de possíveis interferências em seu fazer criativo. A censura, que Caio denominava de "censura-teresinha", impôs às suas obras sanções justificadas pela defesa de valores morais, em nome da tradição, da família e da propriedade, cujos padrões, estabelecidos como "normais" para a vida em sociedade, para o amor e o sexo, restringiam-se a determinados modelos, estanques, e o que destoasse dessas fórmulas era considerado nocivo para a manutenção da harmonia e da paz social.

Nesse sentido, a ideia defendida no possível manifesto neorrealista de renúncia ao individualismo nunca se coadunaria com a escritura de Caio Fernando Abreu e com o seu espírito livre, o que não o livrou, contudo, de ter de submeter-se, em algumas situações, ao crivo da censura sob pena de não conseguir mais publicar seus textos, um castigo também monumental para um escritor como Caio, para quem escrever determinava a sua forma de conectar-se com o mundo. 


\section{REFERÊNCIAS}

ABREU, Caio Fernando. Caio Fernando Abreu: cartas. Org. Italo Moriconi. Rio de Janeiro: Aeroplano, 2002.

Correspondência (1970-1979). In: Caio 3D: o essencial da década de 1970. Rio de Janeiro: Agir, 2005. p. 291-344.

História de um novo tempo: um novíssimo contista brasileiro. O Pasquim, Rio de Janeiro, n. 428, p. 12, de 9 a 15 set. 1977. Carta.

; ANDRADE, Jeferson Ribeiro de; BARRETO, Antonio; EMEDIATO, Luiz Fernando; MARTINS; Julio Cesar Monteiro. Quatro histórias de um novo tempo. O Pasquim, Rio de Janeiro, n. 422, p. 6-9, de 29 jul. a 4 ago. 1977. Entrevista concedida a Félix de Athayde, Cícero Sandroni e Eglê Malheiros.

; ANDRADE, Jeferson Ribeiro de; BARRETO; Antonio; EMEDIATO; Luiz Fernando; MARTINS; Julio Cesar Monteiro; PELLEGRINI JR., Domingos. Histórias de um novo tempo: o novíssimo conto brasileiro. Rio de Janeiro: Codecri, 1977.

ANTÔNIO Barreto. In: ENCICLOPÉDIA Itaú Cultural de Arte e Cultura Brasileiras. São Paulo: Itaú Cultural, 2017. Disponível em: <http://enciclopedia.itaucultural.org.br/pessoa3919/antonio-barreto\%20 \%3E.>. Acesso em: 27 jul. 2017. Verbete da Enciclopédia.

CAIO FERNANDO ABREU. Disponível em: <http://www.pucrs.br/delfos/?p=caiofernando $>$. Acesso em: 29 jul. 2017.

DIP, Paula. Para sempre teu, Caio F.: cartas, conversas, memórias de Caio Fernando Abreu. 3. ed. Rio de Janeiro: Record, 2011.

DOMINGOS Pellegrini. In: ENCICLOPÉDIA Itaú Cultural de Arte e Cultura Brasileiras. São Paulo: Itaú Cultural, 2017. Disponível em: <http://enciclopedia.itaucultural.org.br/pessoa390086/domingospellegrini>. Acesso em: 15 jun. 2017. Verbete da Enciclopédia.

EMEDIATO, Luiz Fernando. Meu caso de amor com Caio Fernando Abreu. Ger@ção Online, São Paulo, [2001?]. Disponível em: <http://www.geracaobooks.com.br/literatura/cartas_caio/caso_caio. php>. Acesso em: 13 ago. 2017.

GALVÃO, Walnice Nogueira. Entrevista: À margem da carta. Teresa. Revista de Literatura Brasileira. São Paulo: Ed. 34, n. 8, 9, 2008. p. 14-29.

GINZBURG, Jaime. A interpretação do rastro em Walter Benjamin. In: SEDLMAYER, Sabrina, 
GINZBURG, Jaime (Org.). Walter Benjamin: rastro, aura e história. Belo Horizonte: UFMG, 2012. p. 107-132.

MACEDO, Gregório. O Pasquim: quarenta lances. Portal Luis Nassif: construindo conhecimento. Disponível em: <https://blogln.ning.com/profiles/blogs/o-pasquim-quarenta-lances $>$. Acesso em: 2 jul. 2017.

MARCOS Coelho Benjamim. In: Enciclopédia Itaú Cultural de Arte e Cultura Brasileiras. São Paulo: Itaú Cultural, 2017. Disponível em: <http://enciclopedia.itaucultural.org.br/pessoa8926/marcos-coelhobenjamim>. Acesso em: 15 ago. 2017. Verbete da Enciclopédia.

MONTEIRO, Rogério. O Pasquim, Rio de Janeiro, n. 424, p. 2, de 12 a 18 ago. 1977. Carta.

MORAES, Marcos Antonio de. Mário de Andrade: epistolografia e processos de criação. Manuscrítica. Revista de Crítica Genética. São Paulo: APML, n. 14, dez. 2006. p. 65-70.

PONTIFÍCIA UNIVERSIDADE CATÓLICA DO RIO GRANDE DO SUL. Delfos - Espaço de Documentação e Memória Cultural. Carta 46217. Correspondência de Domingos Pellegrini Junior para Caio Fernando Abreu. Londrina, PR, 1976, 2 p.

TAVARES, Edélsio. O Pasquim, Rio de Janeiro, n. 424, p. 2, de 12 a 18 ago. 1977.

UM OLHAR sobre Jeferson de Andrade. Escritório de histórias. Belo Horizonte. Disponível em: $<$ http://www.escritoriodehistorias.com.br/modules/news/article.php?storyid=138>. Acesso em: 13 ago. 2017.

Recebido em 27 de agosto de 2017 Aceito em 20 de outubro de 2017 